\title{
The Relationship between Surface Soil Moisture with Real Evaporation and Potential Evaporation in Iraq
}

\author{
Dr. Osama T. Al-Taai ${ }^{1}$, Safa H. Hadi ${ }^{2}$ \\ ${ }^{1,2}$ Department of Atmospheric Sciences, College of Science, Al-Mustansiriyah University, Ministry of Higher Education \\ and Scientific Research, Baghdad - Iraq
}

\begin{abstract}
The aim of this research is to determine the relationship between surface Soil Moisture (SSM) of both Real Evaporation (E) and surface Potential Evaporation (SPE) for thirty years during the period of (1985-2014) for the eight stations (Sulaymaniya, Mosul, Tikrit, Baghdad, Rutba, Kut, Nukhayib, Basrah) in Iraq, from (NOAA) and taking advantage of some statistics such as the Simple Linear Regression (SLR) and the Spearman Rho test. Calculated the monthly average for Soil Moisture, Real Evaporation and Potential Evaporation, and found to increase the values of SPE in hot months and decreased in cold months while opposite to SM There was a strong inverse relationship between them, where the correlation coefficient was in Sulaymaniya -0.91, in Mosul -0.89, in the Rutba -0.92, in Tikrit -0.89, in Baghdad -0.89, in Nukhayib -0.89, in Kut -0.87, and in Basrah -0.83, and there is a high correlation in stations (Basrah, Kut, Nukhayib, and Rutba), while there is an average correlation in the stations (Baghdad and Tikrit), and there is low correlation in the stations (Sulaymaniya, Mosul), we also note an inverse correlation between RE and PE, where there is a low correlation in Sulaymaniya and medium correlation in the Mosul and Rutba stations, and there is a high correlation in the stations (Tikrit, Baghdad, Nukhayib, Kut, and Basrah).
\end{abstract}

Keywords - Soil moisture, Potential evaporation, Real evaporation, Spearman rho test, Iraq.

\section{INTRODUCTION}

The evaporation of the main processes in the water cycle is a link between energy and water budget balance as the water cycle include the release of energy and water vapor transmission and for leading to condensation for precipitation on the surface of the globe. Water flow on the surface of the earth is through surface runoff, groundwater, eyes and others. Then the water cycle ends to the starting point, which is the water surfaces such as lakes, rivers, oceans, seas and the surface of the soil. Unfortunately, this process is one of the most incomprehensible processes in the water cycle. Water is from the liquid to the gaseous state. There are three main reasons for evaporation from the surface of the soil. First, sufficient energy must be available to convert the water from the liquid phase to the gas phase. Second, there is a vapor pressure gradient in the atmosphere sufficient to transform the water from Liquid to vapor. Third, there is sufficient water level in the surface of the soil, which affects the moisture content [1]. Potential Evaporation (PE) can be defined as the amount of evaporation that can be obtained if sufficient water source is available. Real Evaporation (E) is a sum of both Potential Evaporation (PE) and Actual Evaporation (AE) in the soil. Several factors affect the potential evaporation (solar radiation as the most important atmospheric influences, temperature, relative humidity, and wind speed), other factors indirectly affecting (water level, atmospheric stability, soil temperature, latent heat and sensible heat emissions).

The task in the biological processes as it contributes to the process of formation of clouds and then precipitation, which is one of the most important determinants of the cycle of water in nature and therefore measure the amount of potential evaporation to assess the water requirements as well as the need to calculate when planning irrigation projects president widely in many environmental studies, including meteorology, hydrology, agriculture, climate change and affect the surface of the soil, especially at a depth of one to two meters, a key interaction between the earth and the atmosphere is one of the key variables that control the exchange of and the thermal energy between the surface of the Earth and the atmosphere through evaporation and plant transpiration [2]. This variable has multiple links with other anaerobic variables, which makes it very effective predictively although it constitutes a very small layer compared to the global total water but is very important in many of the basic processes of many hydrologists, chemists and biologists are important variables used in many applications (numerical weather predictions, global climate change monitoring, flow forecasting and evaporation modeling) [3]. Spatial and temporal differences of soil water content [4]. 
Agriculture is the sector most economically affected by extreme weather events such as drought. Many other economic sectors of society rely on agro-ecosystems, which are a specific form of human-adapted ecosystems for food production. Can lead to many negative economic and social impacts such as loss of income in agriculture and food industries and high costs for water and production technologies such as irrigation systems [5] [6].

\section{METHODOLOGY}

\section{A. Methods of Analysis}

There were several statistical tests available. Spearman rho was selected. The regression analysis was also selected, particularly the simple linear regression and the use of the P-value for the relationship [7]:

\section{Simple Linear Regression (SLR)}

Is the study of the relationship between two variables only accessible to a linear relationship (i.e. a straight line equation) between these two variables, a parametric test as it is assumed that the data are distributed normally distributed and to find out the value of the regression slope of the regression is calculated by the following linear equation:

$$
\begin{aligned}
& \bar{Y}=a+b \bar{X} \\
& b=\frac{\sum_{i=1}^{n}\left(X_{i}-\bar{X}\right)-\left(Y_{i}-\bar{Y}\right)}{\sum_{i=1}^{n}\left(X_{i}-\bar{X}\right)^{2}}
\end{aligned}
$$

Where b: slope of the regression and found a mile straight line equation (1), a: a constant gradient and demonstrate the value of the lump of axis $\bar{Y}$ for Straight equation (1).

\section{Probability-Value}

It is purely a statistical term, which is a number or the number of measurements used to evaluate the statistical value of a show that was a contrast factor it is an influential factor or not really? If the P-Value is less than 0.05 , the contrast factor it is an influential factor in the variable that we are trying to study the change may consider factor affecting even the value of P-Value equal to 0.1 , but that exceeds 0.1 , this factor should be removed from the form it is ineffective.

\section{Spearman Rho Test}

It is a test of a set of observed data $\left(x_{i}=1,2, \ldots \ldots, n\right)$ is based on the null hypothesis that is, all xi values are independent and have the same distribution and to calculate the Spearman Rho coefficient statistical ranks $\left(\mathrm{r}_{\mathrm{s}}\right)$ must convert the original model to the ranks mediated arranged in descending order in terms of amount and then the value of the account through di $\left(\mathrm{d}_{\mathrm{i}}=\mathrm{k}_{\mathrm{i}}-\mathrm{i}\right)$ where the ( $\mathrm{i}$ $=1,2, \ldots \ldots, n)$ and $r_{s}$ is given by the following $[8]$ :

$$
r_{s}=1-\frac{6 \sum_{i=1}^{n} d_{i}^{2}}{n\left(n^{2}-1\right)}
$$

If the value of $n$ large can choose the value of $r_{s}$ to their importance by calculating the value of $t_{s}$ which is given by equation:

$$
t_{s}=r_{s} \sqrt{\frac{n-2}{1-r_{s}^{2}}}
$$

If the value of $t_{s}$ false calculated within the trusted boundary for the selection of a dual party from this we conclude that there is no trend in the data series and through the "Table 1". Can determine the value of the degree of correlation and interpretation of test transactions.

Table.1: The degree of correlation and interpretation of test transactions [8].

\begin{tabular}{|l|l|l|}
\hline Value & Correlation & Interpretation of relation \\
\hline Less 0.2 & Few & No relation \\
\hline $0.2-0.4$ & Low & Small relation \\
\hline $0.4-0.7$ & Medium & Acceptable relation \\
\hline $0.7-0.9$ & High & Special relation \\
\hline $0.9-1$ & Very high & Strong relation \\
\hline
\end{tabular}

\section{B. The Data and Study Stations}

Was used the monthly average surface soil moisture, surface potential evaporation and real evaporation data for eight different stations in Iraq (Mosul, Sulaymaniya, Tikrit, Baghdad, Rutba, Kut Nukhayib, and Basrah) were used for thirty years (1985-2014) from The National Oceanic and Atmospheric Administration (NOAA) [9], (see "Fig. 1" and "Table 2").

Table.2: The latitude, longitude and altitude of the study stations in Iraq [10].

\begin{tabular}{|l|c|c|c|}
\hline \multicolumn{1}{|c|}{ Stations } & $\begin{array}{c}\text { Latitude } \\
\left({ }^{\mathbf{}} \mathbf{N}\right)\end{array}$ & $\begin{array}{c}\text { Longitude } \\
\left({ }^{\mathbf{}} \mathbf{E}\right)\end{array}$ & $\begin{array}{c}\text { Altitude } \\
(\mathbf{m e t e r})\end{array}$ \\
\hline Mosul & 36.19 & 43.09 & 223 \\
\hline Sulaymaniya & 35.33 & 45.27 & 853 \\
\hline Tikrit & 34.56 & 43.70 & 103 \\
\hline Baghdad & 33.14 & 44.14 & 34 \\
\hline Rutba & 33.02 & 40.17 & 615 \\
\hline Kut & 32.48 & 45.73 & 19 \\
\hline Nukhayib & 32.02 & 42.15 & 305 \\
\hline Basrah & 30.34 & 47.47 & 2 \\
\hline
\end{tabular}




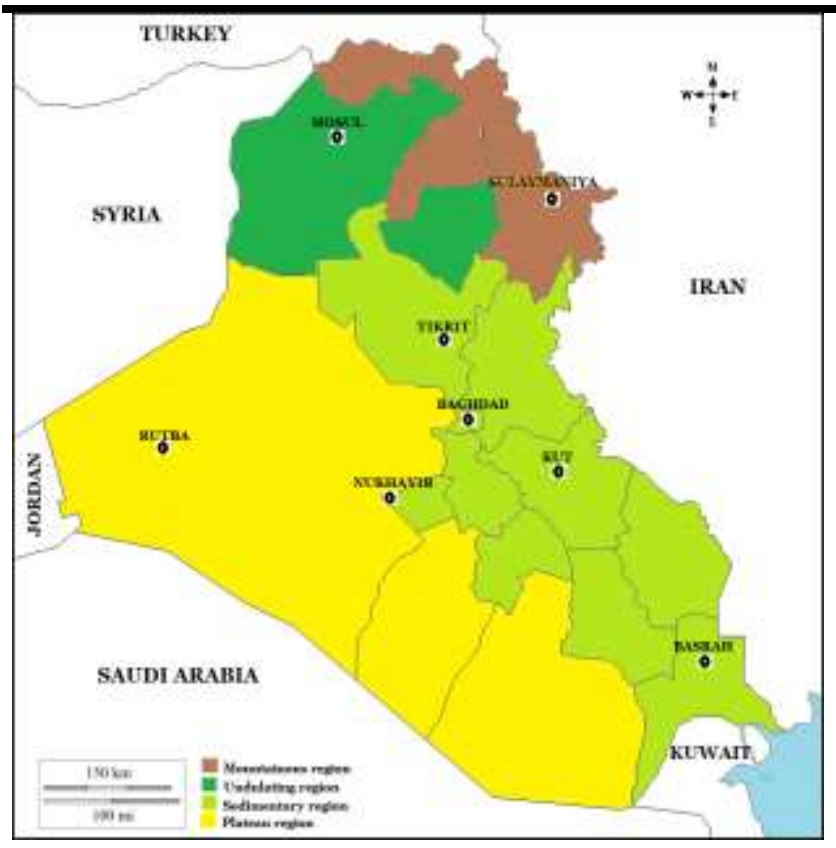

Fig.1: Iraq map, explaining the study stations [10].
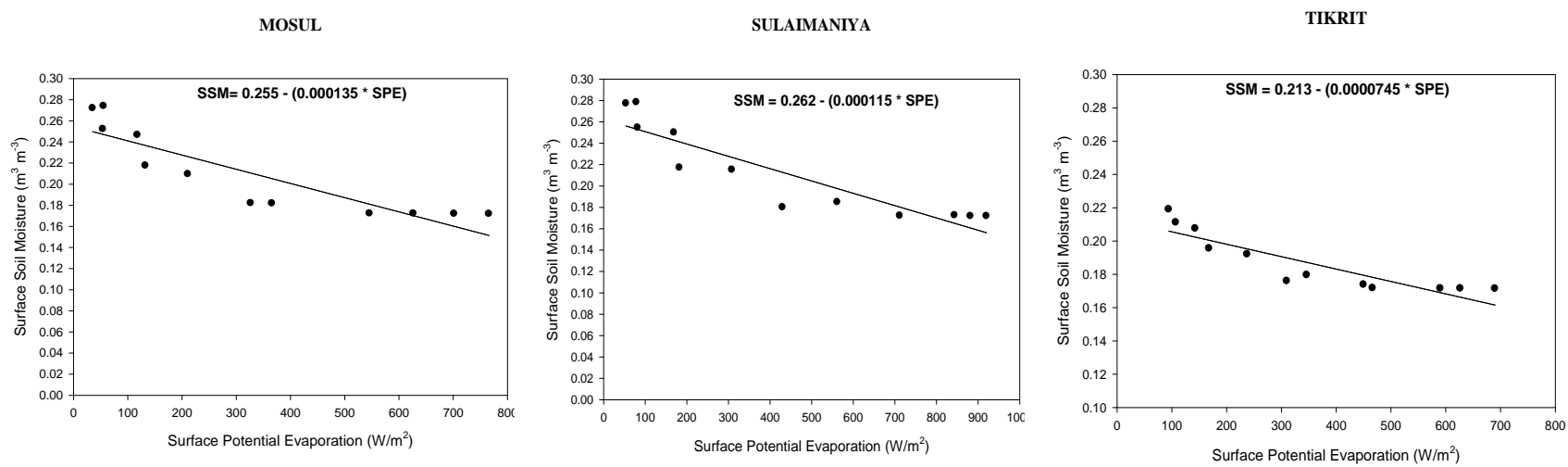

BAGHDAD

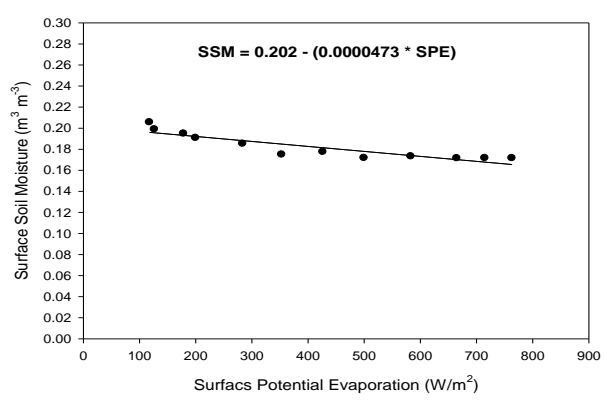

NUKHAYIB

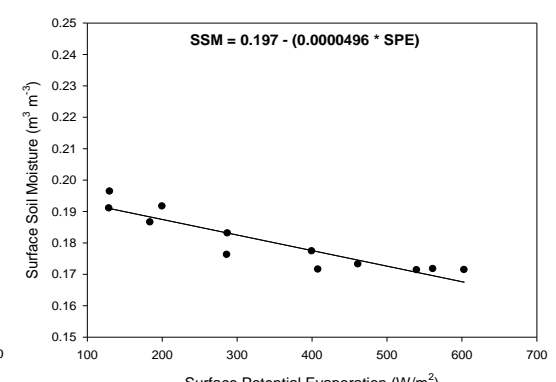

BASRAH

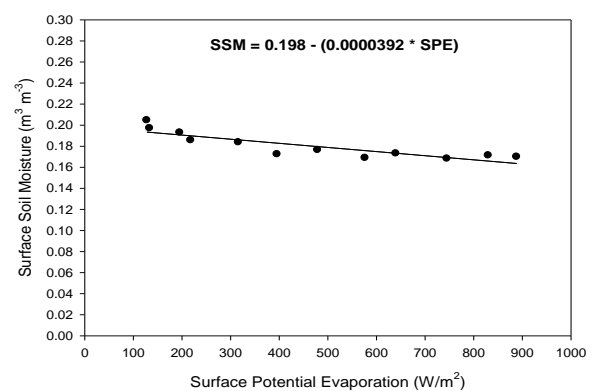

KUT
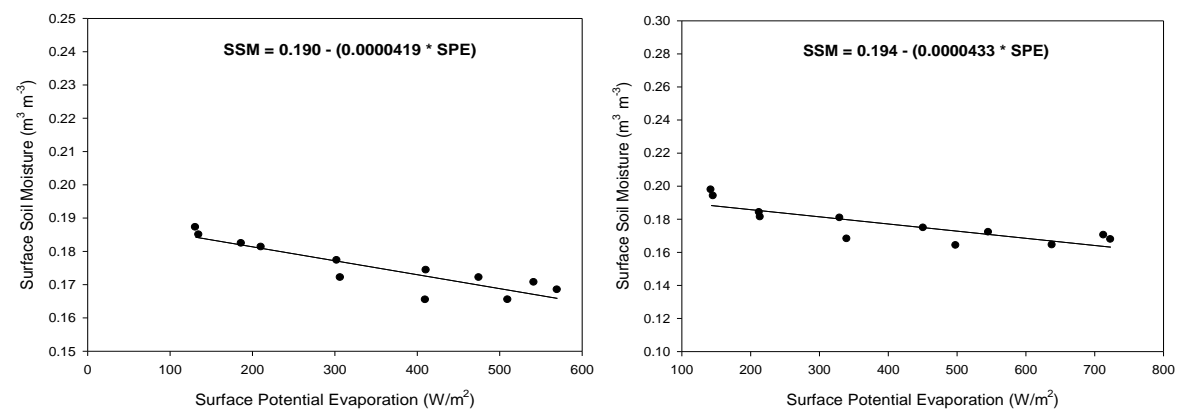

Fig.2: The relationship between the surface potential evaporation (SPE) and surface soil moisture (SSM) of eight different stations in Iraq for thirty years (1985-2014) 
Table.3: Spearman rho test results and Simple Linear Regression (SLR) to find the strength of the relationship between the $S P E$ and $S S M$.

\begin{tabular}{|l|c|l|c|l|}
\hline \multirow{2}{*}{ Station } & \multicolumn{2}{|c|}{ Simple Linear Regression } & \multicolumn{2}{c|}{ Spearman Rho Test } \\
\cline { 2 - 5 } & P-value & \multicolumn{1}{c|}{ Interpretation } & rs & \multicolumn{1}{c|}{ Correlation } \\
\hline Mosul & 0.0001 & Linear relation & -0.89 & High-inverse correlation \\
\hline Sulaymaniya & 0.0001 & Linear relation & -0.91 & Very high-inverse correlation \\
\hline Tikrit & 0.0001 & Linear relation & -0.89 & High-inverse correlation \\
\hline Baghdad & 0.0001 & Linear relation & -0.89 & High-inverse correlation \\
\hline Rutba & 0.0001 & Linear relation & -0.92 & Very high-inverse correlation \\
\hline Kut & 0.0002 & Linear relation & -0.87 & High-inverse correlation \\
\hline Nukhayib & 0.0001 & Linear relation & -0.89 & High-inverse correlation \\
\hline Basrah & 0.0009 & Linear relation & -0.83 & High-inverse correlation \\
\hline
\end{tabular}

\section{The Relationship between E and SSM}

The "Fig. 3", shows that there is a strong positive relationship between E and SSM, where there is a high correlation in the stations (Basrah, Kut, Nukhayib, and Rutba), while there is an medium correlation in stations (Baghdad and Tikrit), There is a low correlation in the stations (Sulaymaniya and Mosul), and also note through the P-Value, there is a nonlinear relationship in stations (Sulaymaniya and Mosul), while there is a linear relationship in the stations (Rutba, Tikrit, Baghdad,
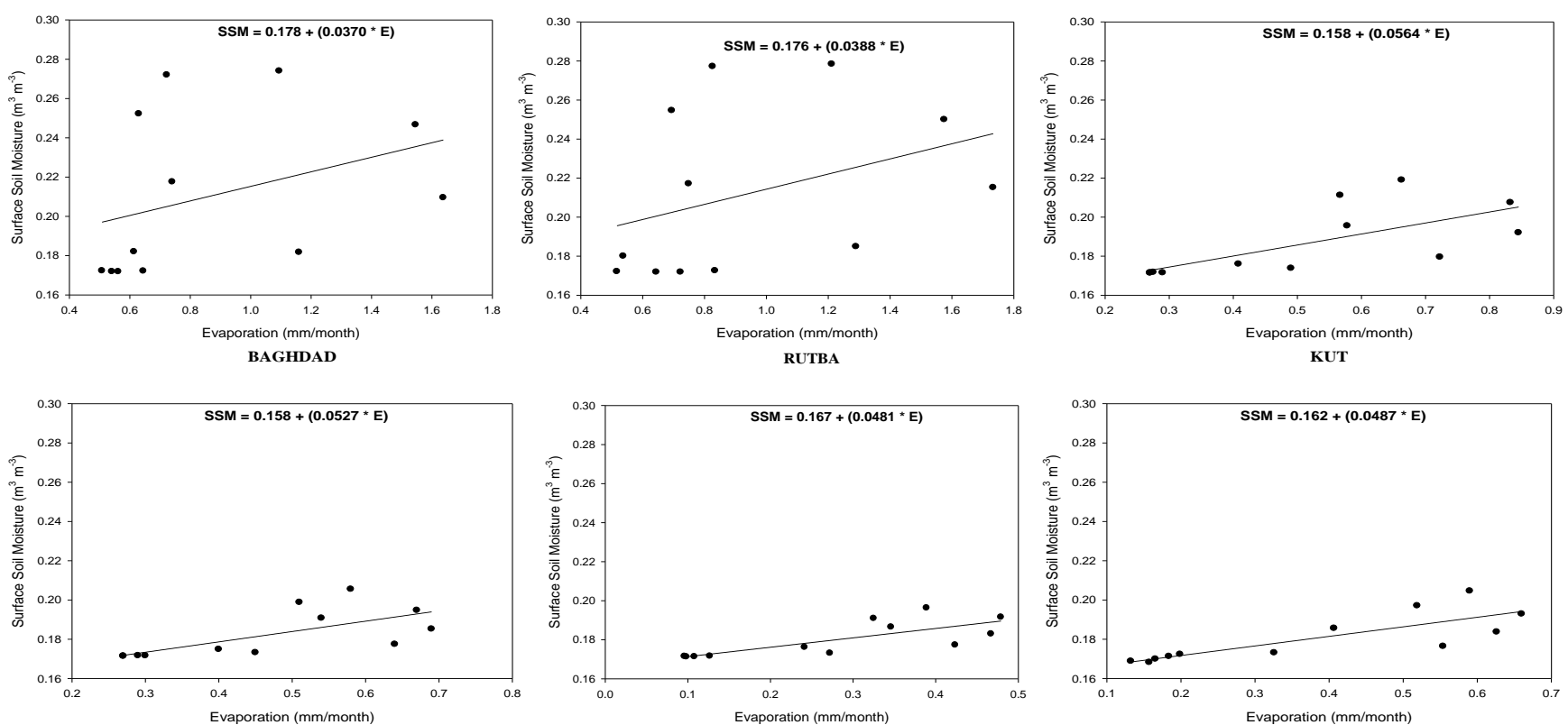

NUKHAYIB
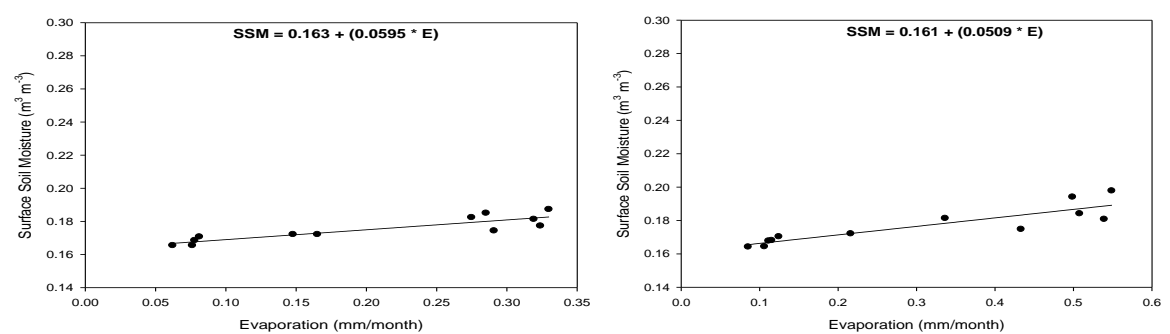

Fig.3: The relationship between the real evaporation $(E)$ and SSM of eight different stations in Iraq for thirty years

(1985-2014) 
Table.4: Spearman rho test results and Simple Linear Regression (SLR) to find the strength of the relationship between the $E$ and SSM.

\begin{tabular}{|l|c|l|c|l|}
\hline \multirow{2}{*}{ Stations } & \multicolumn{2}{c|}{ Simple Linear Regression } & \multicolumn{2}{c|}{ Spearman Rho Test } \\
\cline { 2 - 5 } & P-value & \multicolumn{1}{c|}{ Interpretation } & rs & \multicolumn{1}{c|}{ Correlation } \\
\hline Mosul & 0.2528 & Non-Linear relation & 0.36 & Low-positive correlation \\
\hline Sulaymaniya & 0.2364 & Non-Linear relation & 0.37 & Low-positive correlation \\
\hline Tikrit & 0.0121 & Linear relation & 0.69 & Medium-positive correlation \\
\hline Baghdad & 0.0139 & Linear relation & 0.69 & Medium-positive correlation \\
\hline Rutba & 0.0039 & Linear relation & 0.76 & High-positive correlation \\
\hline Kut & 0.0013 & Linear relation & 0.81 & High-positive correlation \\
\hline Nukhayib & 0.0001 & Linear relation & 0.89 & High-positive correlation \\
\hline Basrah & 0.0001 & Linear relation & 0.88 & High-positive correlation \\
\hline
\end{tabular}

3. The Relationship between $E$ and SPE

The "Fig. 4", shows the relationship between surface real evaporation (E) and potential evaporation (SPE) where there is a strong inverse relationship between them, where we note there is a low correlation in the Sulaimaniya station and the medium correlation in the (Mosul and Rutba) stations and high correlation in the stations (Tikrit, Baghdad, Nukhayib, Kut and Basrah) (see "Table 5").
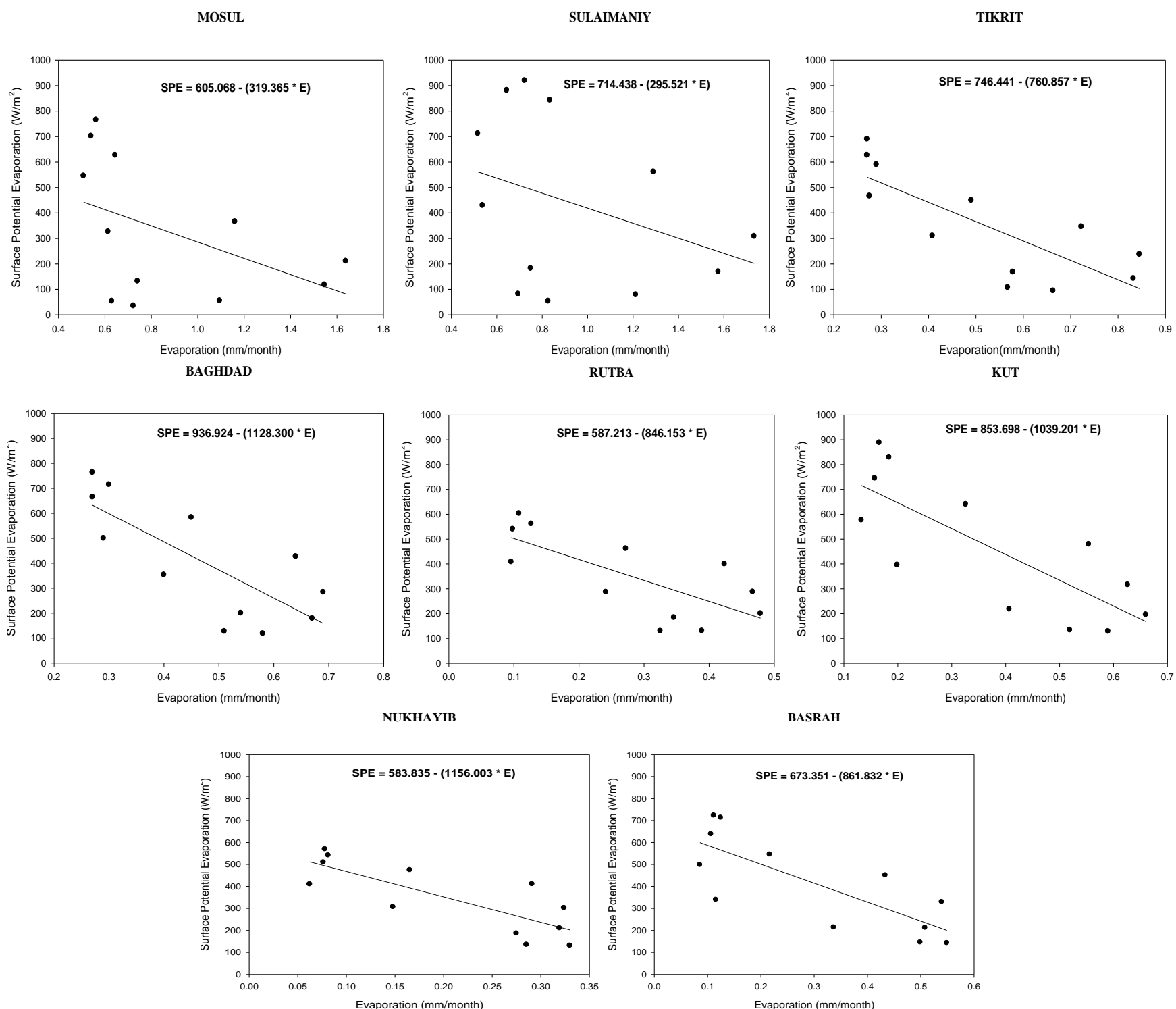

Fig.4: The relationship between the E and SPE of eight different stations in Iraq for thirty years (1985-2014) 
Table 5: Spearman rho test results and Simple Linear Regression (SLR) to find the strength of the relationship between the $E$ and $S P E$.

\begin{tabular}{|l|c|l|c|l|}
\hline \multirow{2}{*}{ Stations } & \multicolumn{2}{c|}{ Simple Linear Regression } & \multicolumn{2}{c|}{ Spearman Rho Test } \\
\cline { 2 - 5 } & P-value & \multicolumn{1}{c|}{ Interpretation } & rs & \multicolumn{1}{c|}{ Correlation } \\
\hline Mosul & 0.1239 & Non-Linear relation & -0.47 & Medium-inverse correlation \\
\hline Sulaymaniya & 0.2527 & Non-Linear relation & -0.36 & Low-inverse correlation \\
\hline Tikrit & 0.0024 & Linear relation & -0.79 & High-inverse correlation \\
\hline Baghdad & 0.0033 & Linear relation & -0.77 & High-inverse correlation \\
\hline Rutba & 0.0074 & Linear relation & -0.73 & High-inverse correlation \\
\hline Kut & 0.0026 & Linear relation & -0.78 & High-inverse correlation \\
\hline Nukhayib & 0.0016 & Linear relation & -0.80 & High-inverse correlation \\
\hline Basrah & 0.0026 & Linear relation & -0.78 & High-inverse correlation \\
\hline
\end{tabular}

\section{CONCLUSIONS}

The results showed a strong inverse relationship between SPE and surface SSM. SPE was found to increase in the southern stations and increase in hot months, in contrast to SSM. It also showed an inverse relationship between $\mathrm{E}$ and SPE. Results there is a strong direct relationship between E and SSM where E occurs only with the presence of water (Soil Moisture). The results show that SPE is an evaporative energy in the atmosphere $\mathrm{E}$ of surface soil moisture because real evaporation is a process of transformation from the liquid phase to the gas phase. E occurs only with soil moisture. E is the sum of SPE and Actual Evaporation (AE) in the soil.

\section{ACKNOWLEDGEMENTS}

An acknowledgment to The National Oceanic and Atmospheric Administration (NOAA) on the data used in this research.

\section{REFERENCES}

[1] E. M. Shaw, "Hydrology in practice $3^{\text {rd }}$ ed.". Stanly Thomas pub. Ltd, U. K, pp. 569, 1999.

[2] C. A. Appelo, and D. Postma,"Geochemistry ground water and Pollution Rotterdam," Balkama Ltd, pp. 536, 1999.

[3] J. Walker, "Estimating Soil Moisture Profile Dynamics from Near-Surface Soil Moisture Measurements and Standard Meteorological Data," Ph.D. dissertation, The University of Newcastle, Australia, 1999.

[4] W. Lingli, and J. Q. John, "Satellite remote sensing applications for surface soil Moisture monitoring a review," Journal of Front, Earth Sci. Chine, vol. 3, issue2, pp. 237- 247, 2009.

[5] J. D. Fast, and M. D. McCorcle, "The Effect of Heterogonous Soil Moisture on a Summer Bar-clinic Circulation in the Central United States," Journal of Mon. Wee. Rev., vol.119, pp. 2140-2167, 1991.

[6] E. A. James, "Soil moisture," Ltd, U. K, 1999. http://www.ghcc.msfc.nasa.gov/landprocess/lp_home .html.

[7] S. Mohammed, "Data Analysis," Site Management and Industrial Engineering, 2009. http://samehar.wordpress.com/2009/08/13/0120809/

[8] Mathematics in Education and Industry (MEI), "Spearman's rank correlation," December 2007.

[9] A. Seidenglanz, and U. Bremen, "Panoply a Tool for Visualizing Net CDF-Formatted Model Output," NASA, February 2016.

http://www.noaa.gov/

[10] General Authority for The Rough Waters of The Iraqi Air and Seismic Monitoring, "Atlas Climate of Iraq for The Period (1961-1990)," Baghdad, Iraq, pp. 8-7, 1994. 